\title{
Bulky Plasmacytoma of the Bone with Intracranial Invasion
}

\author{
Yasuhiro Nagatomo, Hisamitsu Uno, Koichi Maeda, Hitoshi Matsuoka, Toshihiro Tsuruda, \\ Akihiko Okayama, Nobuyoshi Tachibana and Hirohito Tsubouchi
}

\begin{abstract}
A 56-year-old man with left anterior chest pain showed two well-defined tumors in the left anterior chest wall and left parietal region. A large osteolytic lesion in the parietal bone and several punched-out lesions in the temporal bone were revealed by a skull $\mathrm{X}$-ray examination. He showed monoclonal gammopathy (IgG, kappa type) and Bence Jones proteinuria, but no proliferation of plasma cells was observed in the bone marrow. The tissue specimens from both lesions consisted of abnormal plasma cells, indicating plasmacytoma. Although a bulky intracranial plasmacytoma was present, the patient did not exhibit intracranial hypertensive symptoms, or neurological abnormalities.
\end{abstract}

(Internal Medicine 33: 376-379, 1994)

Key words: multiple myeloma, monoclonal gammopathy, magnetic resonance imaging

\section{Introduction}

As most plasma cell neoplasms form multiple tumors in the bone and cause a generalized marrow plasmacytosis, they usually present the appearance of multiple myeloma. Although multiple myeloma diffusely involving the bone is well recognized, solitary skeletal lesions, particularly those in the skull, are a rare manifestation of this disease (1). The invasion of multiple myeloma to the skull is usually noted by osteolytic changes such as a punched-out lesion (2). However, there are few reported cases of bulky intracranial plasmacytoma without generalized plasmacytosis in the bone marrow. We present a case of plasmacytoma with a bulky intracranial tumor not associated with intracranial hypertensive symptoms or neurological deficits.

\section{Case Report}

A 56-year-old man was admitted to our hospital in March 1993, with a two-month history of severe pain in the left anterior chest. A soft mass measuring $70 \times 35 \mathrm{~mm}$ with tenderness was noted on the chest, as well as a soft tumor measuring $60 \times 40 \mathrm{~mm}$ without tenderness in the left parietal region. He reported no intracranial hypertensive symptoms, such as headache, nausea, vomiting, or consciousness disturbance, nor did he show any neurological abnormalities including motor disturbance or congestive fundus.

The results of hematological examination, liver function test, and renal function test were within normal limits other than slightly increased serum alkaline and acid phosphatase values. However, hyperproteinemia $(9.73 \mathrm{~g} / \mathrm{dl})$ with monoclonal gammopathy was found. The serum immunoglobulin levels were: $\operatorname{IgG}, 4,940 \mathrm{mg} / \mathrm{dl} ; \operatorname{IgA}, 174 \mathrm{mg} / \mathrm{dl}$; and $\operatorname{IgM}, 72 \mathrm{mg} / \mathrm{dl}$. Serum M protein was characterized as IgG kappa by immunoelectrophoresis (Fig. 1). Bence Jones protein was also detected in the urine by immunoelectrophoresis. Neither increased number of plasma cells nor appearance of abnormal plasma cells was observed in the left iliac bone marrow.

Chest X-ray examination revealed an osteolytic lesion in the left second rib. A large osteolytic lesion in the left parietal bone and several punched-out lesions in the temporal bone were revealed by a skull X-ray examination (Fig. 2). These lesions were visualized as high-density areas by computed tomography (CT) scanning (Fig. 3). Both T1- and T2-weighted magnetic resonance images (MRI) of the head demonstrated the presence of an iso-intensity mass lesion in the left parietal region (Fig. $4 \mathrm{~A})$. The lesion was enhanced by gadolinium (Gd)-DTPA indicating that it was hypervascular (Fig. 4B). Invasion of plasmacytoma in the cervical, thoracic and lumbar vertebrae were also observed by X-ray examination and MRI.

The diagnosis of plasmacytoma was confirmed by histopathological examination of the intracranial tumor. Figure 5 shows the tissue specimen of the intracranial tumor obtained by surgical resection: it consisted of abnormal plasma cells with large oval and hyperchromatic nuclei and abundant cytoplasm.

The chest wall tumor was treated with irradiation (2 Gy/day,

From the Second Department of Internal Medicine, Miyazaki Medical School, Kiyotake, Miyazaki

Received for publication November 26, 1993; Accepted for publication April 5, 1994

Reprint requests should be addressed to Dr. Koichi Maeda, the Second Department of Internal Medicine, Miyazaki Medical School, Kiyotake, Miyazaki 889-16 


\section{Intracranial Plasmacytoma}

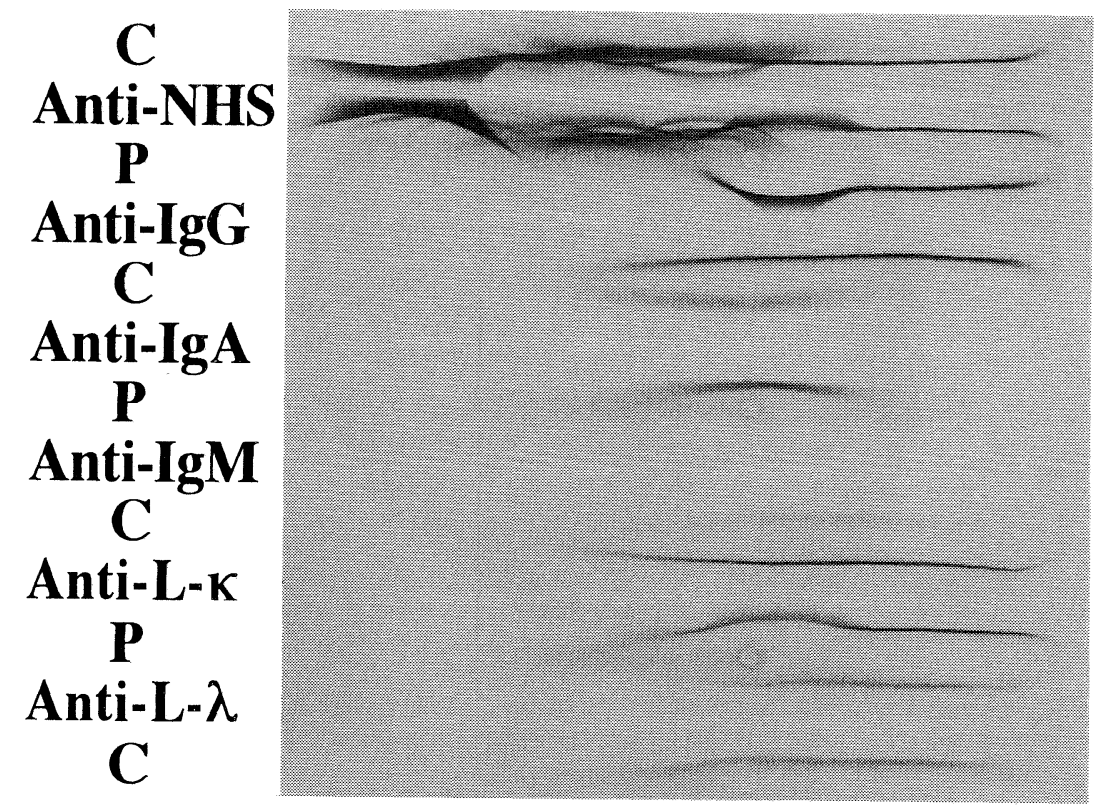

Fig. 1. Immunoelectrophoresis of serum from the patient revealed a light-chain $\mathrm{M}$ protein of the kappa type. C: control, NHS: normal human serum, P: patient.

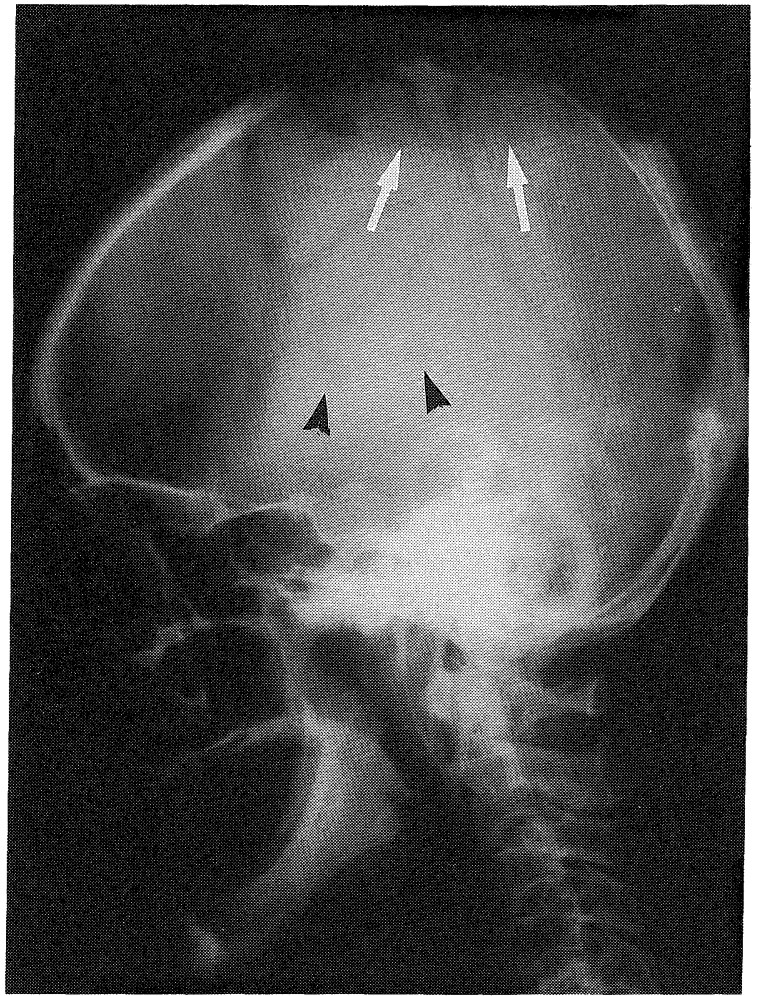

Fig. 2. Skull X-ray film (lateral view) reveals a large and sharply circumscribed osteolytic defect (arrows) in the parietal bone and punchedout lesions (arrowheads) in the temporal bone.

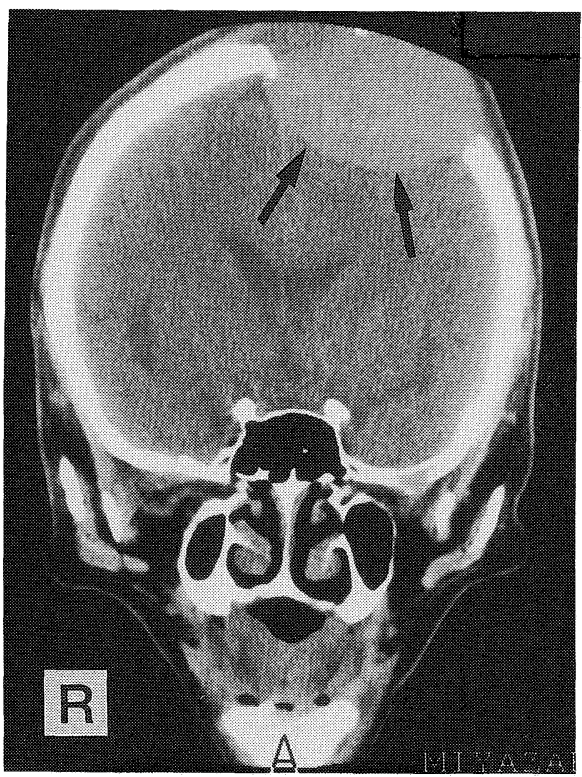

Fig. 3. Plain CT scan reveals a high-density mass lesion (arrows) in the left parietal region.

total $40 \mathrm{~Gy}$ ) combined with ultrasound hyperthermia. The size of the tumor decreased to less than $50 \%$ of the initial size, and the chest pain disappeared after the course of the treatment. Craniotomy for the left parietal mass lesion was performed on April 13, 1993. The intracranial tumor was located in the epidural and subcutaneous space, and invaded into the diploe, but not the dura matter or cerebral cortex. The tumor measured 

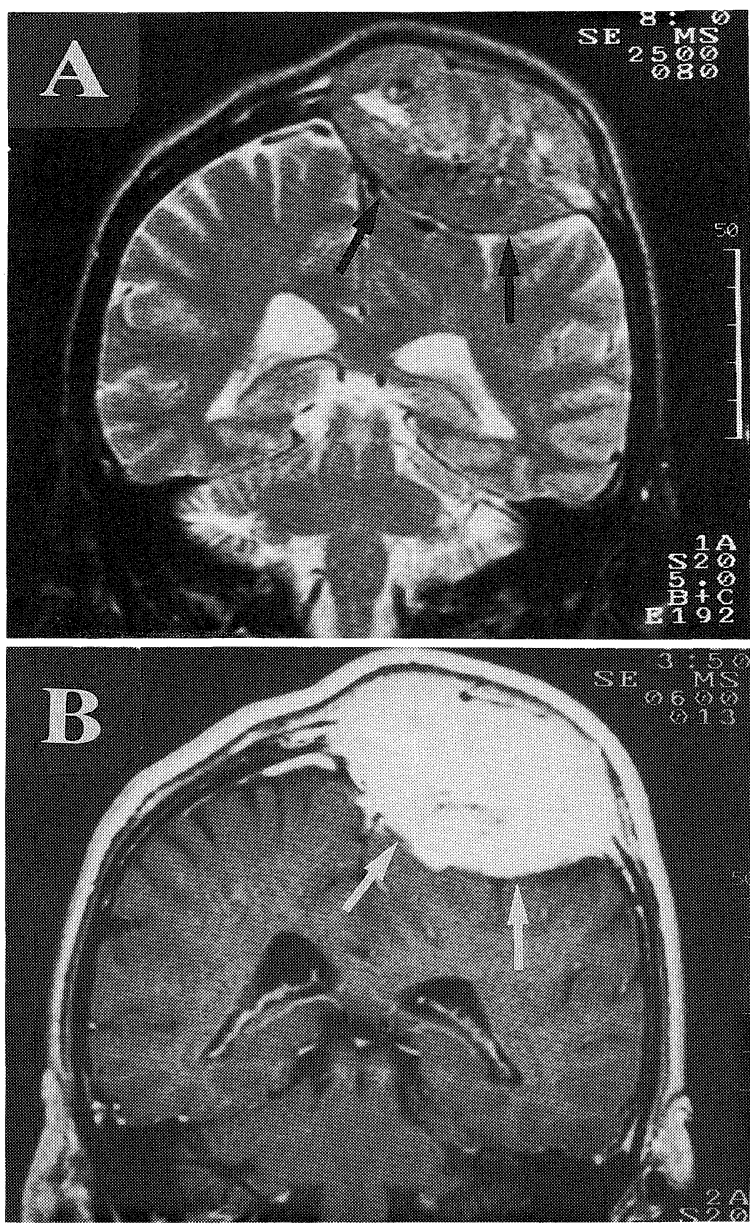

Fig. 4. (A) T2-weighted MRI image demonstrates a heterogenous mass lesion (arrows) with areas of low, iso, and high intensity. (B) The mass lesion (arrows) was enhanced by gadolinium (Gd)-DTPA.

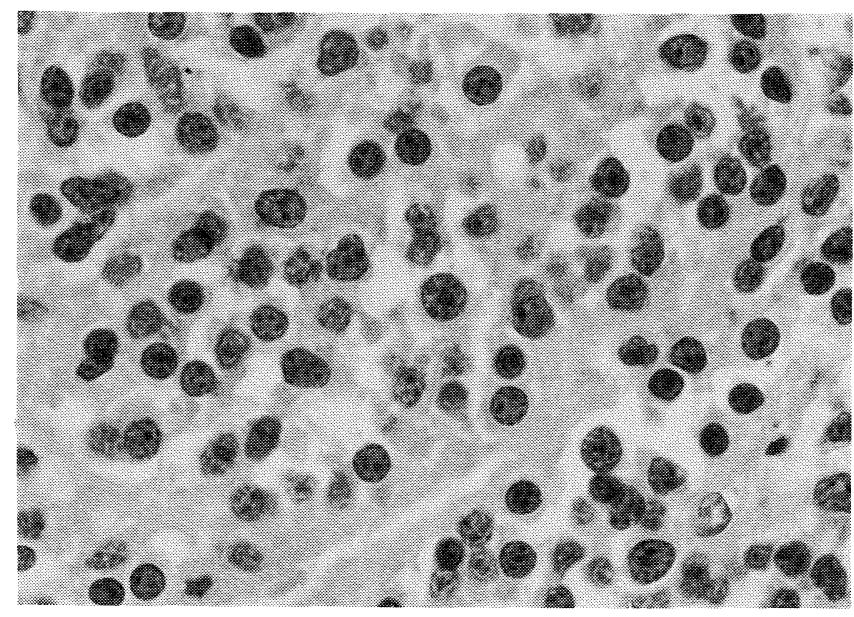

Fig. 5. Tissue specimen of the intracranial tumor obtained by surgical resection showing abnormal plasma cells with abundant oval and hyperchromatic nuclei and abundant cytoplasm (HE stain, $\times 400$ ).
$10 \times 8 \mathrm{~cm}$ and was saucer-shaped. After the removal of the tumor, serum IgG level immediately decreased, from $4,940 \mathrm{mg} /$ $\mathrm{dl}$ to $2,530 \mathrm{mg} / \mathrm{dl}$. The patient's head was then irradiated (total, $40 \mathrm{~Gy})$. He has been doing well as of the time of this writing.

\section{Discussion}

In the present patient, a solitary tumor in the parietal bone and rib, monoclonal gammopathy and Bence Jones proteinuria were present. The tumor in the parietal bone consisted of abnormal plasma cells. However, no proliferation of plasma cells was observed in the bone marrow. Among plasma cell neoplasms, solitary plasmacytoma of bone (SPB) is considered to be a solitary bony tumor consisting of abnormal plasma cells. The criteria for the diagnosis of SPB presented by Holland et al (3) are as follows: biopsy evidence of a plasma cell neoplasm; bone marrow biopsy specimen with negative findings; and absence of evidence of other lesions detected on clinical or skeletal examination. The findings in the present patient did not meet these criteria. However, conversion to multiple myeloma is reported to occur in about $50 \%$ of patients with SPB (3-6). From a different viewpoint, in $2-10 \%$ of multiple myeloma patients, the first manifestation of the disease is a solitary lesion, and most eventually develop overt multiple myeloma. However, the course is often quite protracted, and the patients may live for many years without evidence of dissemination (7). Although, as described above, the tumor of bone in the present patient was not a single tumor, the clinical characteristics in our patient were very similar to those in SPB.

SPB accounts for about $5 \%$ of malignant plasma cell diseases (8). In SPB patients, plasmacytoma which originated from the skull is rare as reported by Holland et al (3), who observed this finding in $5(16 \%)$ of 32 SPB patients. The neurological abnormalities in patients with plasma cell neoplasms originating from the skull or dura usually consist of intracranial hypertensive symptoms, such as headache, nausea, vomiting and visual disturbance (9-11). The absence of any neurological abnormalities in the present patient, who had a bulky intracranial tumor, may have been due to the absence of disturbance of the flow of the cerebrospinal fluid and of cerebral edema.

Intracranial plasmacytoma is an osteolytic lesion of the skull, and this characteristic is useful in the diagnosis of this disease. CT scanning usually reveals the osteolytic lesion as a high density area which is enhanced by contrast medium (911). The bony plasmacytoma lesion is visualized by MRI as an iso- to low-intensity mass on T1-weighted images and as an isoto high-intensity mass on T2-weighted images $(10,11)$. Both the CT and MRI findings in the present patient were those previously described. Furthermore, the masses with abnormal intensity on MRI in our patient were markedly enhanced by GdDTPA. This finding is compatible with the observation that plasmacytoma is usually hypervascular $(9,11,12)$. Although intracranial plasmacytoma presents these characteristic cerebral imaging features, it is sometimes difficult to differentiate from meningioma or metastatic bony tumor without histologi- 
cal examination. Surgical removal of the intracranial plasmacytoma is recommended in the treatment of this disease, and the resected specimen should be histologically examined to confirm the diagnosis. Surgical treatment is also useful, if intracranial hypertension is present. Indeed, we could confirm the diagnosis in the present patient only after examination of the tissue specimen of the intracranial tumor obtained by resection.

The reported median survival time for patients with SPB (114 months) is better than that for patients with multiple myeloma (30 months) (2). Combination therapy with surgical, radiological and hematological treatments may improve the survival time and quality of life in patients with a bulky skull plasmacytoma (13-15). However, most patients develop multiple myeloma, even when the original lesion has been surgically excised or irradiated (3-6). The survival in solitary plasmacytoma once it has progressed to multiple myeloma is similar to that in multiple myeloma (16). The serum protein level, presence of monoclonal gammopathy, and the size of the primary lesion have all been reported to be useful in assessing the risk of conversion of SPB to multiple myeloma (3). All of these features indicate that the present patient is at risk, thus we plan to carefully follow his clinical course.

\section{References}

1) Griffiths DL. Orthopaedic aspects of myelomatosis. J Bone Joint Surg 48B: 703, 1977.

2) Bergsagel DE. Plasma cell myeloma. in: Hematology (Fourth Edition), Williams WJ, Beutler E, Erslev AJ, Lichtman MA, Eds. McGraw-Hill Publishing Company, New York, 1990, p. 1114.

3) Holland J, TrenknerDA, Wasserman TH, et al. Plasmacytoma. Treatment results and conversion to myeloma. Cancer 69: 1513, 1992.

4) Meyer JE, Schulz MD. "Solitary" myeloma of bone. A review of 12 cases. Cancer 34: 438, 1974.

5) Corwin J, Lindberg RD. Solitary plasmacytoma of bone versus extramedullary plasmacytoma and their relationship to multiple myeloma. Cancer 43: 1007, 1979.

6) Knowling MA, Harwood AR, Bergsagel DE. Comparison of extramedullary plasmacytomas with solitary and multiple plasma cell tumors of bone. J Clin Oncol 1: 255, 1983.

7) Osserman ER. Plasma cell myeloma. N Engl J Med 261: 952, 1959.

8) Conklin R, Alexanian R. Clinical classification of plasma cell myeloma. Arch Intern Med 135: 139, 1975.

9) Namba $S$, Ishimitsu $H$, Nishimoto $K$, et al. A case of intracranial plasmacytoma with extradural growth. Neuro Surg 9: 1439, 1981 (in Japanese with English abstract).

10) Sugita K, Kayama T, Ohwada K, et al. A case of multiple myeloma showing intracranial hypertension due to large cranial mass lesion. Noushinkei 38: 625, 1986 (in Japanese with English abstract).

11) Takano K, Ohgami S, Yonemasu Y, et al. A case of multiple myeloma (biclonal type) associated with an intracranial mass invading the skull base and oculomotor palsy. Neurol Surg 19: 1181, 1991 (in Japanese with English abstract).

12) Hayt DB, Blatt CJ, Goldman SM, et al. Hypervascular presentation of multiple myeloma involving the skull, demonstrated on encephalopathy. J Nucl Med 20: 125, 1979.

13) Mill WB, Griffith R. The role of radiation therapy in the management of plasma cell tumors. Cancer 45: 647, 1980.

14) Sporn JR, McIntyre OS. Chemotherapy of previously untreated multiple myeloma patients: An analysis of recent treatment results. Semi Oncol 13: $318,1986$.

15) Hiraoka $M$, Akuta $K$, Nishimura $Y$, et al. Tumor response to thermoradiation therapy: Use of CT in evaluation. Radiology 164: 259, 1987.

16) Chak LY, Cox RS, Bostwick DG, et al. Solitary plasmacytoma of bone: Treatment, progression, and survival. J Clin Oncol 5: 1811, 1987. 